\title{
GÊNERO, SEXUALIDADE E ARTEFATO CULTURAL NA PRISÁO: REFLEXÓES SOBRE O PROJETO ALMA EM CORUMBÁ (MS)
}

\author{
Bruna Fernanda Santos Silveira* \\ Tiago Duque
}

\section{Resumo}

Este artigo analisa as relaçóes entre gênero, sexualidade e processos educacionais em um contexto de sistema prisional feminino. O projeto denominado ALMA (Arte, Lixo e Meio Ambiente) foi promovido e implantado pela Prefeitura Municipal de Corumbá - MS, no ano de 2015. Este projeto, que aliava atividades manuais e grupos de discussão com temas diversos, contou com a participação de quinze detentas. A metodologia para a escrita foi a partir dos relatos de experiência de uma das autoras, que foi responsável por parte das atividades do projeto ALMA. O referencial teórico é, em especial, o pós-crítico (queer, pós-colonial e feminista). A reflexão aqui presente aponta para a "matriz de inteligibilidade de gênero" e a produção de humanidade. A reflexáo aponta ainda para a possibilidade dos artefatos artísticos produzidos por elas serem pensados como "prótese de gênero".

Palavras-chave: Gênero. Sexualidade. Prisão. Artefato Cultural.

\section{INTRODUÇÃo}

Este relato de experiência refere-se às atividades desenvolvidas pelo Projeto ALMA, executado no presídio feminino do município de Corumbá (MS). Com população estimada em cem mil habitantes, o município faz fronteira seca com a Bolívia. Por isso, tem um grande fluxo de migrantes e conta com uma economia diversificada, com atividades nos setores da indústria, agropecuária, agricultura e turismo.

Uma das instituições estatais presentes na cidade é a Agência Estadual de Administração do Sistema Penitenciário (AGEPEN), autarquia vinculada e supervisionada pela Secretaria de Estado de Justiça e Segurança Pública, tendo por finalidades: custodiar as(os) presas(os) provisórias(os), executar as penas de prisão e as medidas de segurança detentivas, amparar as(os) egressas(os), exercer a observação cautelar dos beneficiários da suspensão e livramentos condicionais, administrando os estabelecimentos penais do estado de Mato Grosso do Sul. Segundo informações no site da instituição, para garantir tratamento penal às(aos) custodiadas(os) distribuídas(os) nos três regimes (fechado, semiaberto e aberto), em 45 unidades penais no estado, a AGEPEN possui servidoras(es)

Mestranda no Programa de Pós-Graduação em Educação do Campus Pantanal (PPGE-CPAN) da Universidade Federal de Mato Grosso do Sul (UFMS). E-mail: <brunaf_sjc@yahoo.com.br>.

Doutor em Ciências Sociais pela Universidade Federal do Mato Grosso do Sul, professor do Programa de Pós-Graduação em Educação do Campus Pantanal (PPGE-CPAN) e do Programa em Pós-Graduação em Antropologia Social da Faculdade de Ciências Humanas (PPGAS- FACH) da Universidade Federal de Mato Grosso do Sul (UFMS). E-mail: <duque_hua@yahoo.com.br>.

Instrumento: R. Est. Pesq. Educ., Juiz de Fora, v. 20, n. 1, jan./jun. 2018 
capacitadas(os) para as áreas de: segurança e custódia, assistência e perícia e administração e finanças. O trabalho é desenvolvido em 18 municípios.

O público-alvo do Projeto ALMA é caracterizado por mulheres em privação de liberdade, que estão presas em regime fechado. Ele foi idealizado pela Prefeitura Municipal, por intermédio da Gerência de Políticas Públicas para as Mulheres, e realizado por um dos autores deste artigo, Bruna, enquanto estagiária de psicologia. O estágio foi garantido via o Programa Vale Universidade, que tem como objetivo dar oportunidade para a(o) acadêmica(o) universitária(o) de baixa renda aprimorar a sua formação profissional, mediante concessão de benefício social, composto pelo custeio financeiro e formação profissional. O professor coautor, Tiago, é o orientador das reflexões e contribui com parte da escrita das análises aqui presentes.

O título dado ao projeto está para além das reflexões que a palavra alma desperta. ALMA, neste caso, é o acrônimo das palavras Arte, Lixo e Meio Ambiente. As atividades consistiam em confecção de artesanato (a partir do reuso de materiais que seriam descartados como lixo no ambiente) intercaladas com palestras de temas diversos ("empoderamento" feminino, tráfico de seres humanos, saúde da mulher, violência contra a mulher, sexualidade e normas sociais). No total foram dezesseis encontros com um público fixo de $15 \mathrm{e}$ rotativo de 50 internas, de diferentes idades, religióes, escolaridade, origem, orientação sexual, cor/raça, penas e níveis de progressão de regime.

O contato com os palestrantes e a instrutora de atividades manuais era facilitado pelo Projeto ALMA ser desenvolvido por um órgão público, contudo $\mathrm{o}$ projeto contava com a participação de servidoras(es) de diferentes setores da instituição pública municipal, o que, ocasionalmente, gerava negativas aos convites de participação e certa instabilidade no cronograma das ações. Isso foi superado com encontros para a execução dos artefatos artesanais serem em maior número do que os de palestras temáticas. As normas de segurança do presídio também trouxeram certas limitaçóes ao projeto, afinal, foi preciso reorganizar o planejamento de algumas atividades devido à exigência de respeito da proibição da entrada de produtos como tesouras, isqueiros, sacolas, dentre outros. Isso exigia o pré-preparo de alguns materiais a serem utilizados durante os encontros, ficando apenas a finalização para as mulheres reeducandas fazerem.

Quanto à rotatividade de parte das internas, foi preciso elaborar temas de discussão e artesanatos que pudessem ser finalizados em apenas um dia. As atividades eram feitas uma vez por semana, às quintasfeiras, com duração de duas horas e meia, em uma sala específica para instruçóes e palestras, que possuía mesas individuais no modelo universitário, duas outras mesas retangulares (com aproximadamente $1,5 \mathrm{~m}$ cada) e arcondicionado.

Como ficará claro neste texto, o nosso olhar sobre a mulher em regime de privação de liberdade envolve dimensôes subjetivas e sociais. Neste sentido, podemos considerar que o esperado socialmente da mulher, inclusive da reeducanda do presídio, é transpassado por relaçóes de poder e marcadores sociais da diferença, como gênero e sexualidade. Sobre as reflexóes de gênero, acreditamos que estas devem ir paraalém da naturalização biológica do "sexo", sendo o gênero conceituado por Butler (2003) como uma identidade efemeramente desenvolvida ao passar do tempo por meio da repetição estilizada dos comportamentos que materializam os corpos. Por isso, utilizamos a palavra "sexo" entre aspas em um sentido crítico, na tentativa de problematizar qualquer perspectiva bio-naturalizante desta categoria, destacando, portanto, seu caráter sociocultural. Dito de outro modo, compreendemos "sexo" aqui como sendo "parte de uma prática regulatória que produz os corpos que governa” (BUTLER, 2001, p. 153). 
No que se refere à sexualidade, ela é compreendida aqui nos termos de Foucault (1988), isto é, como uma forma de manifestação de poder que só foi possível no interior de discursos reiterados durante o tempo.

É preciso, portanto, abandonar a hipótese de que as sociedades industriais modernas inauguram um período de repressão mais intensa do sexo. Náo somente assistimos a uma explosão visível das sexualidades heréticas mas, sobretudo - e é esse o ponto importante - a um dispositivo bem diferente da lei: mesmo que se apoie localmente em procedimentos de interdição, ele assegura, através de uma rede de mecanismos entrecruzados, a proliferação de prazeres específicos e a multiplicação de sexualidades disparatas. (FOUCAULT, 1988, p. 48)

Essa conceituação de gênero e sexualidade, permite-nos compreendê-los, enquanto experiências, de forma interseccional, isto é, em relação, autoconstitutivos, ainda que do ponto de vista analítico possamos tomá-los em separado. Dito de outro modo,

Do mesmo modo que se tem assumido que todos os temas de significação racial devem expressarse através da especificidade de uma oposiçâo de classe - e todos os temas de classe, por exemplo, através da especificidade de uma posição de gênero -, todos os temas de gênero deveriam constituir-se necessariamente através da especificidade de uma sexualidade particular e vice e versa (SEDGWICK, 1998, p. 45).

Assim, do ponto de vista teórico, utilizamos nesse artigo uma rede de autoras(es) foucaultianas(os), feministas e pós-coloniais, mas, principalmente, com inspiração queer. O queer é uma categoria local estadunidense que pode significar excêntrico, esquisito, diferente; bem como o pervertido sexual, marginal, estigmatizado ou anormal. Antes de ser usado como uma categoria teórica, o queer foi empregado nos contextos do movimento social estadunidense voltado contra as propostas das organizaçóes e do movimento gay que buscavam garantir direitos civis assimilacionistas e moralizantes. Essa postura teórica altera o foco de uma exclusiva preocupação com a opressáo e libertação dos sujeitos para a análise das práticas institucionais, da produçáo dos conhecimentos sobre o gênero e a sexualidade, e do modo como eles organizam a vida social.

A metodologia para a escrita foi a partir dos relatos de experiência de Bruna, que foi responsável por parte das atividades do projeto ALMA. Bruna e Tiago, a partir de encontros de discussão teórica, produziram a escrita desse artigo articulando teoria e experiência vivida por Bruna em seu campo de estudo.

Sendo assim, para abordar essas temáticas, dividimos este artigo em duas partes. Na primeira, faremos uma reflexáo a respeito do que se pode escutar das detentas, especialmente em relaçáo à sexualidade. Depois, analisaremos o que foi produzido no Projeto ALMA, para pensar o gênero. No entanto, esta separação é apenas analítica. Na prática, gênero e sexualidade estão altamente imbricados, inclusive no contexto prisional. Embora atualmentea administração do regime fechado para cumprimento de penas seja realizada pelo Estado, antes era feita por instituiçóes religiosas que reproduziam em suas práticas educacionais concepções baseadas em um discurso de diferenciação de gênero pelo "sexo". A despeito de tal muança administrativa, até hoje é predominantemente destinada às mulheres detentas a realização de atividades que envolvem trabalhos manuais, saberes domésticos e cuidados infantis (PRIORI, 2012). Oliveria e Santos (2012) corroboram essa afirmação de que "sexo" e gênero estão imbricados nas experiências institucionais diante das detentas, mas apontam ainda para as questôes da sexualidade, especialmente quando afirmam que, em seus estudos,

Constatou-se larga desigualdade no que
se refere às visitas e visitas íntimas às
mulheres encarceradas e aos homens encarcerados,
por inúmeros fatores, que vão desde os entraves
impostos pelos próprios estabelecimentos
prisionais, como restriçáo dos horários de visita e
necessidade de comprovação de vínculo parental,
até discriminaçóes em razáo do gênero, vez que o
homem recompóe suas relaçóes mais facilmente e,
em geral, abandona a companheira reclusa por uma


questão cultural de atribuição do espaço social do crime ao gênero masculino. (2012, p. 236)

Partindo para outras dimensões doaprisionamento feminino, temos as características e vulnerabilidades deste gênero, que justificam esta reflexão, afinal, a partir dela, poderá se pensar em uma educação (da e na prisão) de melhor qualidade em relação às questôes de gênero $\mathrm{e}$ sexualidade das presas. Chamamos educação da prisão a que acontece além do ensino formal oferecido pela instituição, ocorrendo em todos os contatos pessoais e impessoais que as reeducandas realizam dentro da instituição, entre elas e as demais pessoas. A educação na prisão refere-se, apenas, aos processos educacionais formais desenvolvidos pela instituição, comumente desenvolvidas por um setor da Secretaria de Educação, estando contida na educação $d a$ prisão.

\section{1. "ENTÃo DOUTORA": SOBRE SER OU NÁO TIDA COMO HUMANA VIA O DESEJO}

Durante a realização do projeto foi estabelecido um vínculo com as reeducandas do sistema carcerário. As discussôes sobre sexualidade, dinâmica familiar, relaçôes sociais e saúde aliadas aos diálogos informais proporcionados pela confecção de artesanato resultaram em uma relação dinâmica e repleta de "confissóes" das detentas. As relações afetivo-sexuais entre elas eram declaradas sem maiores constrangimentos durante as intervenções realizadas, sejam as atividades de execução do artefato artístico, sejam as palestras. Falas como " $\mathrm{Meu}$ amor está me esperando, ela também está presa" e "[...] ela é (apontando para a mulher que segurava sua mão) minha companheira em tudo aqui" eram feitas espontaneamente.

Quando o assunto era considerado confidencial pelas internas era de "praxe" estas chamarem Bruna em um canto da sala de instruçóes e começar o assunto com um "então doutora". Em uma dessas confissões Cintia (todos os nomes são fictícios) relatou:
Então doutora, você sabe que eu falo de tudo com a minha filha né? Eu já falei de camisinha, do que eu fiz e que vou sair em pouco tempo daqui mas, na última conversa que tive a menina me disse que o pai dela me chamou de sapatão e me perguntou se eu era aquilo mesmo ai eu disse pra ela: depois a gente conversa sobre isso! A senhora sabe como é né doutora?!

Segundo Brito (2007), os vínculos familiares das detentas estão imersos em sentimentos antagônicos e as relações "homoafetivas" (usamos "homoafetivas" entre aspas por considerar a crítica que se faz ao seu significado, especialmente no apagamento da sexualidade em detrimento do afeto - dito de outro modo, destacamos que essas relações também são homoeróticas/sexuais, não simplesmente "afetivas") estabelecidas dentro da penitenciária nem sempre são bem aceitas pela família, sendo que esta mesma família exerce um papel fundamental para o desenvolvimento psíquico das internas (MELLO, 2008). No entanto, considerando o que aponta Medeiros (2010, p. 09), “enquanto a proteção social pelo Estado é deficitária para que contribua no fortalecimento dos vínculos familiares [...], são as redes de sociabilidade internas que vão suprir esta necessidade”. Segundo esta autora, na Penitenciária feminina de Bangu (RJ), ocorre algo muito semelhante ao que pudemos perceber na realidade fronteiriça de Corumbá, afinal, lá e aqui,

$$
\begin{aligned}
& \text { São muitos os entraves para a visita } \\
& \text { familiar, seja em virtude das dificuldades } \\
& \text { financeiras das famílias para se locomoverem até a } \\
& \text { unidade prisional, dificuldade que colaboram para } \\
& \text { o afastamento da família, fazendo com que não } \\
& \text { compareçam as visitaçóes. }(2010, \text { p. } 03)
\end{aligned}
$$

Fora da prisão, no que se refere aos vínculos afetivo-sexuais das atuais reeducandas, parte delas já possuíam relação com o sistema prisional por terem seus companheiros/esposos reclusos, deixando de ter assim determinado apoio em questóes como a educação dos filhos e problemas do cotidiano. Ao adentrarem o sistema prisional, na condição de detentas, as relaçôes de 
companheirismo, afetividade e sexualidade mudam de configuração e as vivências passam a se dar em função do sistema penitenciário, conforme apontado por Granja, Cunha e Machado, "as mulheres passam então a desempenhar dois papéis sociais amalgamados, com fronteiras híbridas, (estar em reclusão e ter o parceiro em reclusão) e ambos com íntimas conexões ao sistema prisional” (2012, p. 4).

Para determinadas reeducandas que possuem companheiros em liberdade, a ausência desses, mesmo quando possuem condiçóes para visitá-las, lhes causa o sentimento de abandono. Imersas em um ambiente disciplinador e controlador, as ações de companheirismo e ajuda recebem maior significado, propiciando o surgimento $\mathrm{da}$ homoafetividade. Isso faz com que elas recebam, por parte da administração carcerária, diversas respostas, dentre elas, distintas puniçóes, como a transferência de presas para ouros presídios, ou até mesmo para solitárias (COLARES, 2012).

Percebemos que essas relações ainda estão em função da instituição prisional que, a priori, é algo transitório, mas os vínculos podem ter caráter permanente com as mesmas características das uniôes estabelecidas em liberdade e/ou com pessoas do sexo oposto. Neste sentido, Brito afirma que:

Quando, entre si, constituem uniōes matrimoniais - novas familias -, entendem que para manter uma relação conjugal é preciso compartilhar a mesma jega, trocar juras de amor, encontrar nas outras a legitimidade da relação, através do compadrio. As madrinhas do casamento são escolhidas em meio àquelas que compartilham a mesma cela ou que são confidentes do casal. (2007, p. 120)

Paradoxalmente a mesma instituição que normatiza e controla é aquela que pode fomentar um ambiente de liberdade para o exercício de novas vivências afetivo-sexuais e familiares. Isso é corroborado pela experiência vivida em Corumbá, associada à bibliografia citada anteriormente, que fez referência a punições em outros contextos prisionais que não se viu, nesses termos, na região fronteiriça em questão.

Dito de outro modo, a partir da experiência do Projeto ALMA, mesmo que não possamos ter uma visão do todo no que se refere às relaçôes afetivosexuais dentro da prisão, percebe-se que, se, por um lado, o Estado é precário nas ações que possam permitir os vínculos familiares, por outro, não busca tornar impossível as relaçóes internas entre as mulheres. A despeito das minúcias que existem nessas relações entre o Estado e elas, evice-versa, é perceptível que, no que se refere à sexualidade, à educação $d a$ prisão autoriza/ permite/torna possível as relações sexuais e amorosas. Assim, estamos focando nos processos educacionais, que são compreendidos aqui para além do trabalho docente propriamente dito, mas como uma dinâmica onde, segundo Guzzo, "as pessoas se constituem em relação com os outros. Nesta circunstância de interação, é que ocorre o processo educativo" (2005, p. 16).

É também por isso que podemos pensar o Estado a partir das reflexóes de Lima (2014). Ela se propóe a trazer para o campo do debate as tensões constitutivas que se situam na relação Estado e política queer, isto é, as formas de reinventar novas possibilidades de existência, exatamente aquilo que o Estado não quer. Dito de outro modo: 1) o Estado precisa ser compreendido a partir do seu caráter múltiplo, isto é, de suas formas singulares no exercício do poder; 2) que, apesar disso e exatamente por isso, há rupturas e escapes que possibilitam novas formas de ser e estar no mundo.

No contexto do cárcere, por exemplo, os processos educacionais estão na rotina de segurança, nas orientaçóes no campo da saúde, da disciplina do convívio coletivo, das normas e convençóes referentes à hierarquia e às mais diferentes atividades diárias. Há, portanto, uma pedagogia que torna legítima as relaçôes afetivo-sexuais entre mulheres na referida instituição pública, a ponto de serem visíveis, de serem expressadas sem qualquer con- 
strangimento. O "segredo", no entanto, estava presente na experiência aqui relatada, como no caso do preconceito que uma das mulheres citadas acima sabe que existe fora da prisão, a ponto de terminar a conversa com a filha ao se ver na iminência de ter que assumir que estava tendo uma relação afetivo-sexual com uma outra mulher, dizendo a ela que "depois a gente conversa sobre isso!"

Assim, parece que, se considerarmos a matriz de inteligibilidade de gênero de Butler (2008), a produção de humanização não é a mesma fora e dentro da prisão. Segundo esta autora, esta referida matriz produz humanidade, via o reconhecimento da heterossexualidade como única possibilidade de humanização: "sexo" feminino = gênero feminino = desejo pelo "sexo oposto"; ou, vice-versa, "sexo" masculino = gênero masculino = desejo pelo "sexo oposto".

Ora, se isso faz sentido para as experiências normativas fora da prisão, dentro, pela forma como as relações afetivo-sexuais entre as mulheres se dão, ela parece ter sido, em parte, flexibilizada. Não apenas em relação à expectativa sobre o desejo entre mulheres, mas inclusive quanto à expectativa de gênero em relação a alguns corpos. Afinal há, reconhecidamente, uma pessoa detida, assignada como sendo do sexo feminino ao nascer, que tem sua autoidentificação masculina aceita pelas outras detentas e pela maior parte das(os) funcionárias(os), inclusive com o nome (social) masculino sendo respeitado.

Pode-se entender o que chamamos de uma flexibilização "em parte", compreendendo a visibilidade dessa experiência via a ideia de regime de visibilidade. Para Miskolci, um regime de visibilidade "traduz uma relação de poder sofisticada, pois não se baseia em proibições diretas, antes em formas indiretas, mas altamente eficientes, de gestão do que é visível e aceitável na vida cotidiana” (2014, p. 62).Com isso, é possível problematizar a flexibilidade da matriz de inteligibilidade apresentada anteriormente, afinal, mesmo com um "sexo" feminino, quando a detenta "performatiza" um gênero masculino, diferente da expectativa normativa, mas sentindo atraçóes afetivo-sexuais por mulheres, o desejo torna-se menos disparatado. Afinal, tornase uma pessoa inteligível como masculina sentindo desejo por pessoas tidas como femininas, e, em última instância, reconhecidas como mulheres. Há, portanto, uma reconfiguração "em parte" dessa matriz, mas com resultado muito próximo do que se espera: que pessoas masculinas se relacionem com outras femininas.

Isso implica, entre outras coisas, em não apenas valorizar as diferenças de gênero e sexualidade, mas entendê-las em suas formas de produção, reprodução e transformação. Para isso, como ensina Brah (2006), a diferença não pode ser vista sempre como um marcador de hierarquia e opressão, isto é, necessariamente depreciativo. Ainda que seja via o aceitável "em parte", ela pode se fortalecer como uma vivência altamente reconhecida e valorizada. Assim, "é uma questão contextualmente contingente saber se a diferença resulta em desigualdade, exploração e opressão ou em igualitarismo, diversidade e formas democráticas de agência política” (BRAH, 2006, p. 374).

\section{ENTRE ANJOS E BOLSAS: OS ARTEFATOS CULTURAIS E A MATERIALIZAÇĀO DO "SEXO" NA PRISÃO}

Sabidamente, a prisão é um espaço disciplinar, isto é, onde certo tipo de poder é exercido, que faz crescer um efeito de utilidade próprio às multiplicidades. Ou seja,

é pra fazer crescer os efeitos utilizáveis do múltiplo que as disciplinas definem táticas de distribuição, de ajustamento recíproco dos corpos, dos gestos e dos ritmos, de diferenciação das capacidades, de coordenação recíproca em relação a aparelhos ou a tarefas (FOUCAULT, 2008, p. 181).

Entendemos a disciplina aqui a partir de Foucault, mas já atualizado pelas reflexóes de Deleuze (1992), que 
nos chama a atenção para o fato de Foucault saber que este modelo disciplinar é histórico, portanto, passível de crise e de uma brevidade em termos de tempo de duração. Segundo ele, o que vivemos hoje não se trata de disciplina, mas de controle, e isso se justifica pelo fato de "Encontrarmo-nos numa crise generalizada de todos os meios de confinamento, prisão, hospital, fábrica, escola, família. A família é um 'interior', em crise como qualquer outro interior, escolar, profissional, etc." (DELEUZE, 1992, p. 220).

Contudo, não se trata aqui de afirmar que não vivemos mais sob uma lógica disciplinar, como chegou a defender Deleuze (1992), antes, reconhecer que há mudanças: das sociedades soberanas, por excelência disciplinares, para as nossas, desde o período após a Segunda Guerra Mundial. Para o autor, não se deve perguntar qual é o regime mais ou menos duro, porque é em cada um deles que se enfrentam as liberaçóes e as sujeiçôes.

Nesse sentido, pensaremos a disciplina na prisão, especificamente no que se refere às atividades do Projeto ALMA, sem deixar de levar em consideração aquilo que é próprio dessas mudanças históricas, o que também precisamos reconhecer em termos de controle. Afinal, se por um lado há de se considerar que os confinamentos podem ser considerados "moldes" e "distintas moldagens", é inegável que também existam as "modulações", isto é, os controles via uma moldagem autodeformante que muda continuamente, a cada instante, ou, para usar uma imagem de Deleuze, como uma peneira cujas malhas mudam de um ponto a outro.

Para isso pensaremos os artefatos artesanais feitos pelas mulheres na prisão enquanto artefatos culturais, isto é, "dispositivos pedagógicos" em termos de gênero e sexualidade. Estes dispositivos têm relação direta com a ideia de disciplina discutida aqui, que "funcionam cada vez mais como técnicas que fabricam indivíduos úteis" (FOUCAULT, 2008, p. 174). Mas funcionava também como dispositivos de controle, e não exclusivamente de disciplina. Isso nos permite pensar as relações de poder de um jeito diferente, não apenas dentro da prisão em si, pois, hoje o controle "é de curto prazo e de rotação rápida, mas também contínuo e ilimitado, ao passo que a disciplina era de longa duração, infinita e descontínua" (DELEUZE, 1992, p. 223).

Dentre tudo o que foi possível produzir junto com as detentas, trazemos para a análise dois artefatos artísticos: o anjo e a bolsa. $\mathrm{O}$ anjo foi realizado com catálogos de cosméticos, bola de isopor, cola, papel pardo picado e flores secas. A bolsa era produzida a partir de caixa de leite longa vida vazia, elástico, botão, cola quente e tecido.

Enquanto o anjo foi escolhido pelo Estado (prefeitura) para ser produzido pelas dententas, e representa culturalmente a religiosidade, um ser não humano (de outro mundo), não sexual, metafísico, que comumente carrega valores de branquitude e pureza, sem maldade ou crime, a bolsa é algo absolutamente laico, sexualizado, mundano, humanizador, uma prótese de gênero, nos termos de Preciado (2002).

Pensamos prótese de gênero não como sendo uma essência, mas como trânsito. É um efeito múltiplo e não tem uma origem única (PRECIADO, 2002). Por isso, neste contexto da experiência aqui relatada, a bolsa, escolhida por elas para serem produzidas, e não pelo Estado, é uma prótese de feminilidade. Isso porque, "a prótese é um acontecimento de incorporação", como tantas outras zonas de produção do gênero. "Historicamente, é a única forma de 'ser corpo' em nossas sociedades pósindustriais. A prótese não é abstrata, não existe senãoaqui e agora, para este corpo e neste contexto" (PRECIADO, 2002, p. 168). Neste sentido, Preciado afirma que, em nossos dias, todos os gêneros serão protéticos: "a masculinidade e a feminilidade serão termos que designam estruturas históricas (e quiçá caducas) de incorporação" (PRECIADO, 2002, p. 168-169). 
Parece-nos apropriado pensar a prótese aqui como parte da materialização do "sexo", nos termos de Butler, afinal, ela, a bolsa, compóe a performance de gênero das mulheres na prisão, visto que, diferente dos anjos, as bolsas ficaram com elas para serem levadas para a cela, para o cotidiano mais geral do presídio. Essa materialização se dá via os vários atos de gênero, que "cria a ideia de gênero, e sem esses atos, não haveria gênero algum, pois não há nenhuma 'essência' que o gênero expresse ou exteriorize [...]" (BUTLER, 2003, p. 199). Eles se dão em meio aos efeitos de poder que constituem os corpos, dentro e fora da prisão: "os corpos só surgem, só permanecem, só sobrevivem dentro das limitaçóes produtivas de certos esquemas reguladores com alto grau de generalização" (BUTLER 2008, p. 14). Isto é, o corpo passa a ser compreendido e reconhecido por ser sujeito de dinâmicas sociais, como lócus de articulação de relaçóes e legitimador de princípios sobre a sociedade (MONTEIRO, 2012).

Como pensamos poder na perspectiva foucaultiana, é possível perceber que a resistência está sendo produzida nestas relaçôes de poder, via a própria produção protética destes artefatos artísticos e a repetição dos atos de gênero, afinal, a educação $d a$ prisão, ainda que disciplinar, permitiu a escolha da criação de bolsas individualizadas, inclusive para que algumas das mulheres pudessem presentear mães e filhas durante as visitas. É nesse sentido que a prótese, como controle de gênero, está para além dos muros da prisão. Assim, seja os anjos ou as bolsas, há em sua produção formas de pensar o gênero e a sexualidade, afinal, são "dispositivos pedagógicos" do que se está posto para as mulheres, presas ou não.

Além do que foi discutido até aqui, estes artefatos, em especial a sua produção e circulação, também apontam para o quanto, mesmo no cárcere, as mulheres possuem agência. $\mathrm{O}$ agenciamento aqui é entendido a partir das "possibilidades no que se refere à capacidade de agir, mediada cultural e socialmente" (PISCITELLI,
2008, p. 267), logo, jamais de forma autossuficiente, autonomamente. Antes, essa agência é possível sob as lógicas de inteligibilidade social e das posiçôes de poder que elas ocupam no contexto da prisão.

Esse agenciamento reforça a ideia de o quanto gênero não é algo dado, uma essência a-histórica ou uma vivência fora das relaçóes de poder. Ele apresenta o quanto ser mulher é uma experiência sociocultural, cheia de artefatos e, consequentemente, pedagogias culturais. Afinal,

\begin{abstract}
O gênero só existe na prática, na experiência e sua realização se dá mediante reiteraçóes cujos conteúdos são interpretações sobre o masculino e o feminino, em um jogo, muitas vezes contraditório e escorregadio, estabelecido com as normas de gênero. $\mathrm{O}$ ato de pôr uma roupa, escolher uma cor, acessórios, o corte de cabelo, a forma de andar, enfim, a estética e a estilística corporal, são atos que fazem o gênero. Que visibilizam e estabilizam os corpos na ordem dicotomizada dos gêneros. (BENTO, 2006, p. 228).
\end{abstract}

Nesse sentido, para além dos dois artefatos em si, do anjo e da bolsa, a própria prisão é um artefato cultural repleto de outros. Ela, enquanto uma arquitetura protética, contribui para com os "currículos culturais" que, "entre outras coisas, produzem valores e saberes, regulam condutas e modos de ser, fabricam identidades e representações, constituem certas relaçôes de poder" (SABAT, 2001, p. 9).

\section{ConsideraçóEs finais}

A experiência das mulheres detentas participantes do Projeto ALMA, ainda que de forma preliminar, foi refletida neste texto a partir de diferentes conceitos: disciplina, controle, matriz de inteligibilidade de gênero, prótese de gênero, regime de visibilidade, agência, entre outros. Eles, articulados, nos permitem considerar que a prática das relações homoeróticas e a produção de artefatos artísticos, entendidos como artefatos culturais, 
estão presentes nos processos educacionais, nos termos em que aqui os definimos.

As relaçóes afetivo-sexuais entre as mulheres dentro da prisão, diantedos motivos aqui já expressados, parece nâo ser uma ameaça à produção de inteligibilidade de gênero, nem de materialização do "sexo" feminino, contrariando parte da matriz de inteligibilidade de gênero, especialmente quando da expectativa de humanização via a heterossexualidade. Por sua vez, há, nesse mesmo processo, ressignificaçóes que retornam as experiências para próximo do esperado em termos normativos, quando uma pessoa masculina, ainda que mulher, sente-se atraída por mulheres femininas. O mesmo náo ocorre quando, no contato de uma delas com a filha que foi visitá-la, a experiência relatada de fora do presídio, é vista compreconceito, assim a matriz de inteligibilidade de gênero parece ser reiterada. São os resultados dos regimes de visibilidade contemporâneos, que estão na prisão e, também, fora dela.

Além disso, pudemos compreender que a bolsa, como prótese de gênero, compóe os processos de materialização de um gênero, logo, também de um "sexo" via os atos repetidos, via a performance que, no contexto de inteligibilidade cultural, torna os corpos reconhecíveis, humanizados, femininos. Afinal, a bolsa está culturalmente ligada às mulheres em suas performances de gênero. Esse processo, por sua vez, se dá em meio a experiências de controle e disciplina, via o exercício do poder.

A educação da prisão, ao mesmo tempo que, via o Projeto ALMA, por parte do Estado, e não das mulheres detentas, propóe a produção de anjos, seres sem "sexo", também permite que elas escolham produzir bolsas, inclusive para presentear outras mulheres, de fora do cárcere. Materializaçáo, performance e próteses são reiteradas em meio à realidade disciplinar, mas também de controle a ponto de ser um desejo das mesmas, que as alocam coerentemente nas performances femininas de gênero, correspondendo a parte da matriz já discutida, um exemplo de como a agência é exercitada nos processos de diferenciação e reconhecimento das mulheres em questão.

São esses "moldes" e essas "moldagens", isto é, a disciplina e o controle, em termos de expectativas da matriz de inteligibilidade de gênero que precisam ser problematizadas enquanto processos educacionais que humanizam as mulheres detentas. Pelo relato de experiência aqui presente, conclui-se que os direitos em relação às questóes de gênero podem ser melhor vivenciados, mesmo em condiçóes de privação de liberdade, por meio de uma educação de qualidade e preocupada com essa temática. Afinal, a educação da prisão, vista no viés analítico aqui utilizado, permite um maior aprofundamento dos processos de reconhecimento e produção de humanidade, algo de fundamental importância para mulheres reeducandas, socialmente vulneráveis.

GENDER, SEXUALITY AND CULTURAL ARTIFACT IN PRISON: REFLECTIONS ON THE ALMA Project IN
Corumbá (MS) Abstract

This article analyzes the relations between gender, sexuality and educational processes in a context of the female prison system. The project called ALMA (Art, Garbage and Environment) was promoted and implemented by the City Hall of Corumbá - MS, in the year 2015. This project, which combined manual activities and discussion groups with different themes, counted on the participation of fifteen prisoners. The methodology for writing was based on the experience reports of one of the authors who was responsible for part of the ALMA 
project activities. The theoretical background is, in particular, the post-critical (queer, post-colonial and feminist). The reflection in this report points to the "matrix of gender intelligibility" and the production of humanity. The reflection also points to the possibility of the artistic artifacts produced by them as being understood as 'prosthesis of gender".

Keywords: Gender. Sexuality. Prison. Cultural Artifact.

\section{GÉNERO, SEXUALIDAD Y ARTEFACTO} CULTURAL EN LA CÁRCEL: REFLEXIONES Sobre el Proyecto ALMA EN Corumbá (MS)

\section{Resumen}

Este artículo de experiencia analiza las relaciones entre género, sexualidad y procesos educativos en un contexto de sistema carcelario femenino. El proyecto denominado ALMA (Arte, Basura y Medio Ambiente) fue promovido e implantado por el Gobierno Municipal de Corumbá - MS, en el año 2015. Este proyecto, que combinaba actividades manuales y grupos de discusión con temas diversos, contó con la participación de quince mujeres detenidas. La metodología utilizada para la escritura fue a partir de los relatos de experiencia de una de las autoras responsables por parte de las actividades del proyecto ALMA. El referencial teórico es, en especial, el post-crítico (queer, post-colonial y feminista). La reflexión presente en este relato apunta a la "matriz de inteligibilidad de género" y la producción de humanidad. La reflexión también apunta a la posibilidad de los artefactos artísticos producidos por ellas ser pensados como "prótesis de género".

Palabras clave: Género. Sexualidad. Cárcel. Artefacto Cultural.

\section{REFERÊNCIAS}

BENTO, Berenice. A reinvençâo do corpo: sexualidade e gênero na experiência transexual. Rio de Janeiro: Garamond, 2006.

BRAH, Avtar. Diferença, diversidade, diferenciação. Cadernos Pagu, n. 26, p. 329-376, 2006. Disponível em: $<$ http://www.scielo.br/pdf/cpa/n26/30396.pdf>. Acesso em: 8 jun. 2017.

BRITO, Mirella A. de. O caldo na panela de pressão: um olhar etnográfico sobre o presídio para mulheres em Florianópolis. Dissertação (Mestrado) - Programa de Pós-Graduação em Antropologia, Universidade Federal de Santa Catarina, Florianópolis, 2007.

BUTLER, Judith. Cuerpos que importan: sobre los limites materiales y discursivos del "sexo". 2. ed. Buenos Aires: Paidós, 2008.

BUTLER, Judith. Problemas de gênero: feminismos e subversão da identidade. Rio de Janeiro: Civilização Brasileira, 2003.

BUTLER, Judith. Corpos que pesam: sobre os limites discursivos do "sexo". In: LOURO, Guacira Lopes. (Org.). O corpo educado: pedagogias da sexualidade. Belo Horizonte: Autêntica, 2001. p. 152-172.

COLARES, Leni Beatriz Correa. Sociação de mulheres na prisâo: disciplinaridades, rebeliôes e subjetividades. Tese (Doutorado) - Programa de Pós-Graduação em Sociologia, Universidade Federal do Rio Grande do Sul, Porto Alegre, 2012.

DELEUZE, Gilles. Conversações. São Paulo: Editora 34, 1992.

FOUCAULT, Michel. Vigiar e punir: nascimento da prisão. 35. ed. Petrópolis: Vozes, 2008.

FOUCAULT, Michel. História da sexualidade I: a vontade de saber. Rio de Janeiro: Ed. Graal, 1988. 
GRANJA, Rafaela Patrícia Gonçalves; CUNHA, Manuela Ivone P. da; MACHADO, Helena. Intimidades em (des) conexão com a prisão: as relaçóes amorosas de mulheres antes e durante a reclusão. In: CONGRESSO PORTUGUÊS DE SOCIOLOGIA. Sociedade, crise e reconfiguraçóes, 7., 2012, Universidade do Porto.

GUZZO, Raquel S. L. Escola Amordaçada: compromisso psicológico com este contexto. Albertina. M. Martínez (Org.). Psicologia escolar e compromisso social: novos discursos, novas práticas. Campinas: Alínea, 2005. p. 17-29.

LIMA, Fátima. É possível um ESTADO* que abarque a multidão queer? Breves considerações sobre a política sexual na biopolítica contemporânea. Revista Periódicus, v.1, n.1, p. 191-205, maio-out. 2014. Disponível em: <https://portalseer. ufba.br/index.php/revistaperiodicus/article/view/10155>. Acesso em: 3 ago. 2014.

MEDEIROS, Luciana L. de. Mulheres e cárcere-reflexóes em torno das redes de proteção social. In: ENCONTRO NACIONAL DE HISTÓRIA ORAL, 10., 2010, Recife. Testemunhos: história e política. Recife: Universidade Federal de Pernambuco, 2010.

MELLO, Daniela C. de. Quem são as mulheres encarceradas? Dissertaçáo (Mestrado em Psicologia Clínica) - Faculdade de Psicologia, Pontifícia Universidade Católica do Rio Grande do Sul, Porto Alegre, 2008.

MISKOLCI, Richard. Negociando visibilidades: segredo e desejo em relaçôes homoeróticas masculinas criadas por mídias digitais. Bagoas - Estudos gays, gêneros e sexualidades, v.8, n. 11, p. 51-78, 2014. Disponível em: <https://periodicos. ufrn.br/bagoas/article/view/6543/5073>. Acesso em: 15 maio 2017.

MONTEIRO, Marko Synésio Alves Monteiro. Os dilemas do humano: reinventando o corpo em uma era (bio)tecnológica. São Paulo: Annablume, 2012.

OLIVERIA, Magali; SANTOS, Andre F. Desigualdade de gênero no sistema prisional: consideraçóes acerca das barreiras à realizaçâo de visitas e visitas íntimas às mulheres encarceradas. Caderno Espaço Feminino, Uberlândia-MG, v. 25, n. 1, p. 236-246, 2012. Disponível em: <http://www. seer.ufu.br/index.php/neguem/article/view/15095/11088>. Acesso em: 21 mar. 2018.

PISCITELLI, Adriana. Internseccionalidades, categorias de articulação e experiências de migrantes brasileiras. Sociedade e Cultura, Goiânia, v.11, n. 2, p. 263-274, 2008.
Disponível em: < https://www.revistas.ufg.br/fchf/article/ view/5247/4295>. Acesso: 22 jan. 2018.

PRECIADO, Paul/Beatriz. Manifesto Contra-sexual. Madrid: Opera Prima, 2002.

PRIORI, Claudia. Mulheres fora da lei e da norma: controle e cotidiano na Penitenciária Feminina do Paraná (1970-1995). Diálogos, Maringá, v. 16, n. 2, p. 821-827, 2012. Disponível em: <http://periodicos.uem.br/ojs/index.php/Dialogos/ article/view/36159/18719>. Acesso em: 21 mar. 2018.

SABAT, Ruth. Pedagogia cultura, gênero e sexualidade. Estudos Feministas, Santa Catarina, ano 9, p. 9-21, 2001. Disponível em: <https://periodicos.ufsc.br/index.php/ref/ article/view/S0104-026X2001000100002/8891> Acesso em: 21 mar. 2018.

SEDGWICK, Eve Kosofsky. Epistemologia del armario. Barcelona: Ediciones de La tempestad, 1998.

Enviado em 7 de fevereiro de 2018 Aprovado em 20 de março de 2018 